
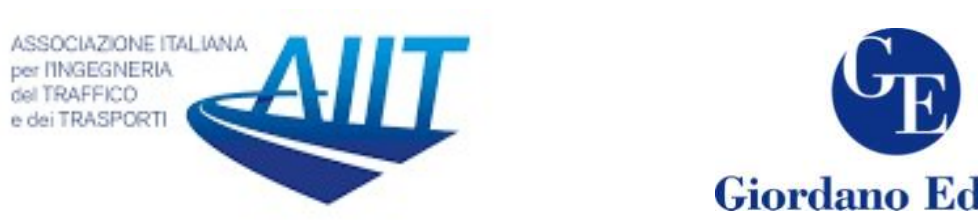

Giordano Editore

\title{
Alternative transport means in city centers: exploring the levels of use, typical behaviours and risk factors
}

\author{
Victoria Gitelman $^{1 *}$, Anna Korchatov ${ }^{1}$, Shalom Hakkert ${ }^{1}$ \\ ${ }^{1}$ Transportation Research Institute, Technion City, Haifa 32000, Israel
}

\begin{abstract}
Alternative transport means (ATMs) such as e-bicycles, electric scooters, mobility scooters (for the elderly) and segways, suggest improved mobility for individual road users, with associated benefits of reduced congestion and energy savings. However, the urban space is not adapted to incorporate these means, while ATMs use the infrastructure built for vehicles or pedestrians and are not always in accordance with traffic rules. The growing use of ATMs is accompanied by an increase in related injury. This study aimed to characterize the scope of ATM use in Israeli cities, their behaviours at typical urban locations and risk factors, and to consider solutions for safer ATMs integration into the urban space. The study data were collected by means of an observational survey at 50 representative urban intersections, in 9 city centers. Regression models were adjusted to explore the relationships between the presence of various road users. Profiles of ATM users and their behaviours were examined. The models showed a direct relation between the presence of traditional transport means and ATMs, meaning that they are used for the same destinations in the city. The e-bicycle presence was generally similar to that of regular bicycles; it was low on roadways related to vehicle traffic, but more tangible on sidewalks, related to pedestrian traffic. At sites with higher vehicle volumes, more ATMs rode on sidewalks. Among most ATM users, except for mobility scooters, children below 18 presented about a third and the majority were young adults aged 19-34. Most ATM riders did not wear helmets. The study findings indicated that the ATM volumes in the cities are not negligible and should be accounted for in planning urban facilities. For safer ATMs integration in the cities, more bicycle facilities and wider sidewalks are needed, accompanied by enforcement and publicity efforts.
\end{abstract}

Keywords: Alternative transport means; presence; urban intersections; road user behaviours.

\section{Introduction}

Alternative transport means (ATMs) such as e-bicycles, electric scooters, mobility scooters and segways (Figure 1) were designed to improve the mobility of individual road users. Research showed that ATMs are suitable for short trips in urban areas, with associated benefits of improved accessibility, reduced traffic congestion, lower energy consumption and positive health effects (Blais et al., 2012; Jonhson and Rose, 2013; Fyhri and Fearnley, 2015). However, the urban space is not adapted to absorb the new means.

\footnotetext{
*Corresponding author: Victoria Gitelman (trivica@technion.ac.il)
} 
The ATMs use urban infrastructure settings built for other road users, such as vehicles and pedestrians, and not always in accordance with traffic rules which leads to conflicts between various road users (Petzoldt et al., 2017; Gitelman et al., 2017). The use of ATMs is growing in many countries, including Israel, whereas it is accompanied by an increase in related injury (Schepers et al., 2014; Gertner Institute, 2015). Moreover, current design guidelines for planning urban streets, such as Guidelines (2009) in Israel, ignore the ATMs' presence in urban traffic.

In general, there is a need to explore the current situation in order to consider solutions for an effective integration of ATMs into urban space. Thus, this study aimed to characterize the ATMs use in Israeli cities, based on a field survey at typical urban locations, and by considering the scope of ATMs presence in urban traffic, their common behaviours and associated risk factors. The study findings are supposed to provide an empirical basis for indicating infrastructure solutions and other measures needed for promoting safer ATMs integration in urban traffic.

a

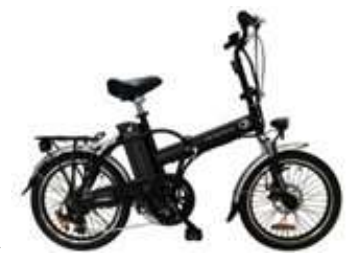

b

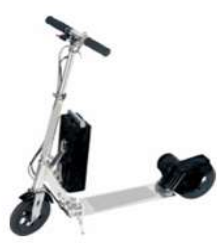

$\mathrm{c}$

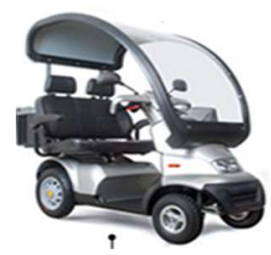

d

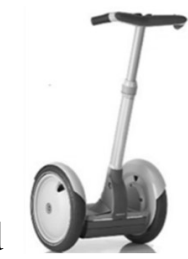

Figure 1: Examples of ATMs: (a) an e-bicycle; (b) an electric scooter; (c) a mobility scooter; (d) a segway.

\section{Literature survey: traffic regulations and previous research on ATMs use and behaviours}

\subsection{E-bicycles}

Electric power-assisted bicycles or e-bicycles (Fig.1, a) are bicycles with two-wheels installed one after the other and fitted with an electric engine and a battery. The electric assistance to the rider reduces the physical efforts required for riding. Therefore, ebicycles are associated with a potential to expand the role of cycling in urban transport (Rose, 2012). Studies showed that the durations and distances of trips performed by ebicycle riders increased compared to trips on conventional bicycles and that they may replace private car travel for daily purposes (Jonhson and Rose, 2013; Fyhri and Fearnley, 2015). In addition, e-bicycles are useful for people who are not able to ride conventional bicycles due to physical limitations (MacArthur et al., 2014). In many countries, ebicycles' use has increased recently; in Europe, the growing use was observed particularly in Germany, the Netherlands, Austria, Switzerland, Italy and France (Dozza et al., 2013; Fishman and Cherry, 2016). As estimated, in Israel, over 200,000 e-bicycles were sold in a period of three years.

In Israel, similarly to Europe, an e-bicycle should satisfy the conditions defined by EN 15194 (2009): the engine power is limited to 250 watts, speed is up to $25 \mathrm{~km} / \mathrm{h}$ and obligatory pedaling. E-bicycles meeting these requirements do not need a driving license, insurance and vehicle license, and can move on bicycle lanes, like a regular bicycle. By contrast, vehicles that exceed these requirements belong to a category of mopeds/motorcycles, with an obligation of licensing and insurance. According to Traffic regulations (2016) in Israel, only people aged 16 and above are allowed to ride e-bicycles. 
In urban areas, wearing a helmet is mandatory for cyclists under the age of 18. E-bicycles are allowed to ride on bicycle facilities and on roads, and are not allowed to ride on sidewalks, crosswalks or other pedestrian places.

Empirical studies from the USA and Germany showed that e-cyclists usually ride faster than conventional cyclists, yet, the speed differences are not big, e.g. the mean speeds of e-bicycles were higher by $2-3 \mathrm{~km} / \mathrm{h}$ compared to regular bicycles (e.g. Langford et al., 2015). Research findings from Sweden and Germany indicated that the chance of ebicycle riders to be involved in conflicts with other road users is higher compared to conventional bicyclists, particularly at intersections and near crosswalks (e.g. Petzoldt et al., 2017). Evaluations in the Netherlands showed that the risk of e-cyclists to be injured in a road accident is higher compared to conventional cyclists (Schepers et al., 2014). In Israel, the data from the national trauma registry indicated a drastic increase in the amount of injuries associated with e-bicycles and electric scooters, over the last years (Gertner Institute, 2015), that was clearly associated with the increased use of these transport means.

\subsection{Electric scooters}

The electric scooter or e-scooter (Fig.1, b) has an electric engine and a battery. According to the Israeli standard, its maximum power of engine should be up to 250 watts, the maximum speed is up to $25 \mathrm{~km} / \mathrm{h}$; the engine is operated by a hand throttle and it stops when the brake is applied. The structure of the e-scooter is similar to that of a regular scooter, but because of battery and engine adding it is heavier and faster. To ride an e-scooter, there is no need for a driver license, a vehicle license or insurance. Regulations concerning e-scooters are not uniform across countries (Lavallee, 2004) and are currently re-considered in many European countries due to a rapid increase in the use of e-scooters in the cities. In Israel and in some other countries, e.g. in Belgium, e-scooters have to ride on bicycle paths or on the roadway, when the bicycle path is unavailable, while riding on sidewalks is forbidden. In contrast, e.g., in the State of Washington, escooters are allowed to ride on sidewalks. In some countries, such as Israel and a number of US States, the rider should wear a helmet. In Israel, riding is permitted from the age of 16; age limits for use exist in some other countries, e.g. in Belgium, Germany, France, the Netherlands.

People using the e-scooter are typically young, mostly use it for recreational purposes and short trips in cities (Lavallee, 2004), yet, recently, a growing use by commuters is noticed. Similarly, the majority of injuries in e-scooter accidents are to children and youth who were injured close to home, often as a result of loss of control of the scooter and falling (Marcy and Rutherford, 2005; Griffin et al., 2008). In Israel, about half of all injuries in e-bicycles' and e-scooters' accidents were to children up to 17 years old (Gertner Institute, 2015).

\subsection{Mobility scooters}

The mobility scooter is an electric vehicle with 3 or 4 wheels, a floor and a handlebar (Fig.1, c). It moves at a slow speed (in Israel, up to $12 \mathrm{~km} / \mathrm{h}$ ) and should usually travel on sidewalks. Among various ATMs, the mobility scooter is the most appropriate for elderly and people with walking disabilities (Blais et al., 2012; Jancey et al., 2013). Studies in developed countries indicated that the use of mobility scooters may improve elderly people mobility and the quality of life and that there are signs of upward trends in their use (Blais et al., 2012; Thoreau, 2015; Gitelman et al, 2017). 
To drive a mobility scooter, in most countries, there is no need for a license or insurance. The legislation allows a person who ceased driving of motor vehicles due to health reasons, to use this means for mobility purposes. Mobility scooters are supposed to travel on sidewalks and pedestrian paths. However, to enable that, the sidewalks should be paved, wide and flat, free of obstacles, sloped near pedestrian crossings and available throughout the city. When this is not the case, mobility scooter riders use the roadways, hence, increasing disturbance to vehicle traffic and the risk of injury (Gitelman et al, 2017). In Israel, injuries and fatalities were reported in mobility scooters' accidents on the roads (CBS, 2015). Mobility scooters' injuries in road accidents were also reported in Australia and the Netherlands.

\subsection{Segways}

The segway is a vehicle designed for a single passenger with two wheels attached to one axle and driven by an electric engine (Fig.1, d). Its steering, stopping and stabilization are done by tilting the body and the electrical stabilizing system. According to the Traffic regulations (2016), the total width of a segway is up to $90 \mathrm{~cm}$, the maximum speed is 13 $\mathrm{km} / \mathrm{h}$, and it should ride on sidewalks. The regulations concerning segways vary among countries. For example, in most US States, they are permitted to ride on sidewalks, bicycle paths, and certain roads (Lavallee, 2004). Riding a segway does not require a license or insurance. The segways are mainly used for traveling in closed areas, e.g., industrial zones or university campuses, short-distance rides and recreational purposes. Studies showed that the use of segways on sidewalks and in pedestrian areas does not endanger pedestrians and segway riders, and thus, segways can be allowed on urban pedestrian infrastructure (Castonguay and Binwa, 2006; Miller et al., 2010). Injuries in accidents with segways are not common but an increase in injuries resulting from the use of segways was reported, e.g. in Vienna (Roider et al., 2016).

\section{Methodology}

The study aimed to collect empirical data with regard to the use of ATMs in Israeli cities and their behaviours at typical urban settings. The study data were collected by means of an observational survey at urban intersections, of three types: signalized intersections on urban arterials, signalized intersections on collector streets and roundabouts, whereas all locations are situated in the vicinity of city centers or lay on main traffic routes to such and, thus, are representative of typical urban traffic.

Preliminary field trips indicated that a higher potential for meeting ATMs exists in more densely populated cities (near the seaside of the country), with flat landscape and medium-high socio-economic levels. Such cities were selected from the whole list of cities in the country, with over 50,000 residents, while providing a range in terms of the city size, socio-economic levels and geographical areas. The final list of the survey comprised 50 intersections, in nine cities, including 10 roundabouts, 10 signalized intersections on urban arterials and 30 signalized intersections on collector streets. Since divided roads, with a built median and more than one traffic lane per direction, are common in city centers in Israel, all signalized intersections were selected on divided roads.

The observational survey was conducted on workdays during the main hours of urban activities, between 8 AM-8 PM, with 6 hours per each site. Three layers of data were collected: (1) full counting of the ATMs (of four types) entering a junction from any direction; (2) periodic sampling of background data - motor vehicles, pedestrians, regular 
bicycles, from each direction (every ten minutes); (3) main characteristics of the ATM users (age group, gender, place of riding, etc.). The data were collected manually, by two trained observers per site.

The count data were processed to produce hourly figures, per each site and per each type of sites. The indicators of presence of various ATMs were estimated related to vehicle and pedestrian traffic, and compared between various types of sites (using a ztest). Then, Pearson correlations were examined and regression models were adjusted to explore the relationships between the presence of various road users. The characteristics of the ATM users were analyzed to create their profiles, at various types of sites.

Since all the variables (except for the site type) were continuous, linear regression models were applied for predicting the ATMs presence at urban intersections. We used Shapiro-Wilk tests for checking the distributions; if necessary, a logarithmic transformation of values was applied to some variables to adjust to a normal distribution. The models' development had two steps. First, full linear regression models (Cohen et al., 2013) were adjusted in $R$ software version 3.3.2 using an $L M$ function. Two versions of the models were developed, with three explanatory variables (site type, vehicle traffic, pedestrian traffic) and four explanatory variables (as previously plus regular bicycle traffic). The models' goodness-of-fit was measured by a percentage of explained variance and by the Fisher test. At this step, the contribution of various explanatory variables was examined. Then, to obtain the final models, we ran a stepwise linear regression in SAS 9.4 software, using a proc reg procedure with both forward and backward variable selection. At this step, the percentage of explained variance and the model significance were used to examine the model's suitability.

\section{Results}

\subsection{Traffic counts at urban intersections}

Table 1 presents estimates of the mean hourly counts of total vehicle and pedestrian traffic and the ATMs passing through the intersection, by type of sites. Figure 2 presents estimates of the ratios between the number of e-bicycles and regular bicycles to the total number of vehicles and the number of pedestrians passing through the intersection, per hour, by type of sites.

Table 1: Hourly means of traffic counts at urban intersections, by type of site.

\begin{tabular}{lccccccccc}
\hline $\begin{array}{l}\text { Type of junction } \\
\text { [No of sites] }\end{array}$ & $\begin{array}{c}\text { Motor } \\
\text { vehicles }\end{array}$ & $\begin{array}{c}\text { Pedest- } \\
\text { rians }\end{array}$ & $\begin{array}{c}\text { Bicycles, Bicycles, } \\
\text { on } \\
\text { roadway sidewalks }\end{array}$ & $\begin{array}{c}\text { E- } \\
\text { on } \\
\text { bicycles, } \\
\text { on } \\
\text { roadway }\end{array}$ & $\begin{array}{c}\text { E- } \\
\text { bicycles, Mobility } \\
\text { on } \\
\text { sidewalks }\end{array}$ & Electric & Seg- \\
scooters* scooters* ways*
\end{tabular}

Maximum values are shown in parentheses (.) * On sidewalks and roadway together 


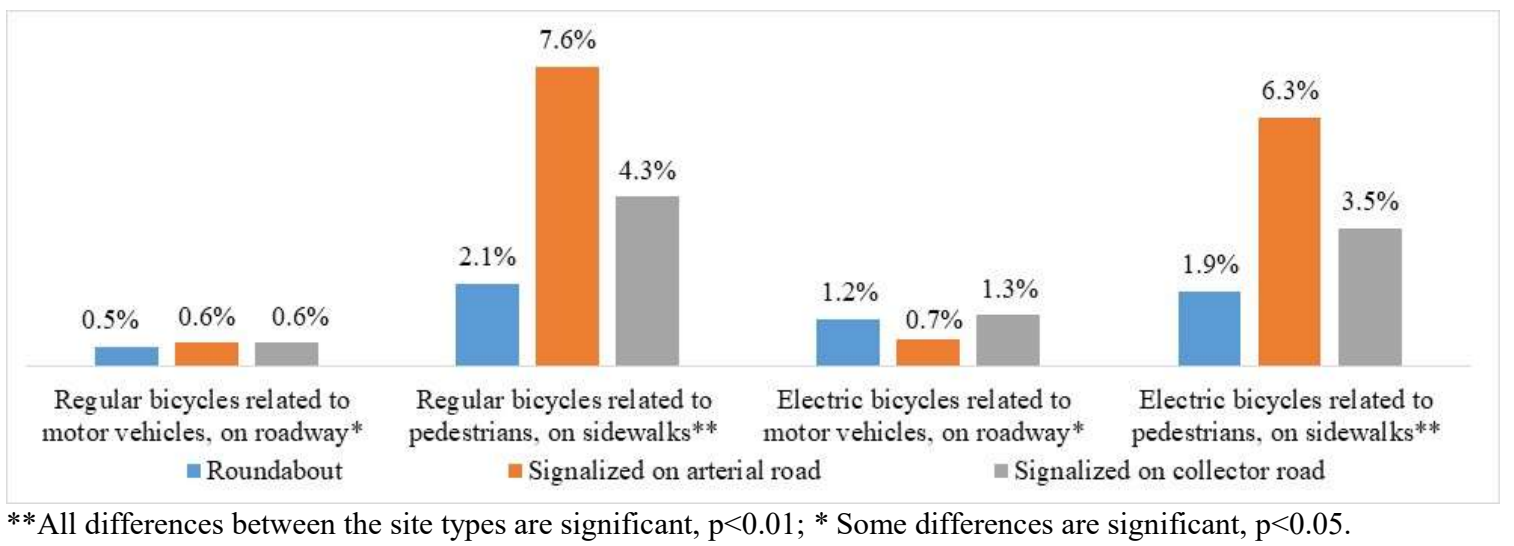

Figure 2: Ratios between the number of e-bicycles and regular bicycles to the number of vehicles and pedestrians passing through the intersection, per hour, by type of sites.

The results showed that the mean hourly numbers of e-bicycles observed at signalized intersections were around 50, at roundabouts about 23 (on roadways and sidewalks together), but the values varied widely between the sites. At some sites, about 80 ebicycles were observed, per hour, on sidewalks or on the roadway. The mean hourly numbers of other ATM types, per intersection, were substantially lower, in the range of 1-3. The extent of e-bicycle traffic was generally similar to that of regular bicycles. At all types of sites, the presence of both bicycle types was more tangible on sidewalks, related to pedestrian traffic: about $2 \%$ at roundabouts, $6 \%-8 \%$ at signalized intersections on urban arterials, about $4 \%$ at other signalized intersections, and was lower related to motor vehicle traffic, between $0.5 \%-1 \%$. As found, more e-bicycles choose to travel on roadways at roundabouts and on collector streets, while on arterial roads they prefer to travel on sidewalks. More mobility scooters were met at roundabouts than at signalized intersections. Apparently, such results reflect a tendency of ATM users to choose "safer" travel conditions for their riding routes.

In the correlation analyses, significant positive correlations were found between motor vehicle traffic and the numbers of regular bicycles, e-bicycles, e-scooters and total ATMs, and a significant negative correlation with the presence of mobility scooters (Table 2). For pedestrian traffic, significant positive correlations were indicated with the numbers of mobility scooters, e-bicycles and total ATMs, for regular bicycles - with e-bicycles, escooters and total ATMs. In addition, in the roundabout sample, a negative significant correlation was stronger between the vehicle traffic and the presence of mobility scooters $(\mathrm{p}<0.01, \mathrm{r}=-0.78)$ and positive significant correlations were stronger between pedestrian traffic and the number of e-bicycles and total ATMs $(\mathrm{p}<0.05, \mathrm{r}=0.63-0.67)$.

Table 2: Pearson correlation coefficients between the numbers of various road users, at urban intersections (all sites together).

\begin{tabular}{lcccccc}
\hline Road users & \multirow{2}{*}{ Pedestrians } & $\begin{array}{c}\text { Regular } \\
\text { bicycles }\end{array}$ & E-bicycles & $\begin{array}{c}\text { Mobility } \\
\text { scooters }\end{array}$ & $\begin{array}{c}\text { E- } \\
\text { scooters }\end{array}$ & $\begin{array}{c}\text { Total } \\
\text { ATMs }\end{array}$ \\
\hline Motor vehicles & -0.056 & $0.399^{* *}$ & $0.446^{* *}$ & $-0.362^{* *}$ & $0.379^{* *}$ & $0.417^{* *}$ \\
Pedestrians & & 0.059 & $0.260^{*}$ & $0.444^{* *}$ & 0.165 & $0.289^{*}$ \\
Regular bicycles & & & $0.623^{* * *}$ & -0.146 & $0.742^{* * *}$ & $0.628^{* * *}$ \\
E-bicycles & & & & -0.019 & $0.842^{* * *}$ & $0.997^{* * *}$ \\
Mobility scooters & & & & & -0.081 & 0.053 \\
E-scooters & & & & & & \\
${ }^{*} \mathrm{p}<0.05^{* *} \mathrm{p}<0.01^{* * *} \mathrm{p}<0.001{ }^{*} \mathrm{p}<0.01$ & & & & & \\
\end{tabular}


Evidently, regular bicycles, e-bicycles and all ATMs together appear at the same sites in the city as motor vehicles and pedestrians, indicating a direct relation between the presence of "traditional" and new road users. A difference was found for mobility scooters, which mostly come to the same sites as pedestrians, but their numbers drop at sites with higher vehicle traffic, seemingly, reflecting their preference to low and slow traffic conditions that was also indicated by previous research (Gitelman et al., 2017).

\subsection{Models for predicting ATM numbers in traffic, at urban intersections}

In the first step of the models' development, it was found that the effect of the site type was not significant and did not contribute to the prediction of the ATMs' traffic. At the same time, the addition of regular bicycle traffic as an explanatory variable improved the quality of models. Hence, the final models for predicting ATM numbers in traffic were adjusted using three explanatory variables (vehicle, pedestrian and regular bicycle volumes), as presented in Table 3. (The models for predicting separate numbers of escooters and segways were not fitted due to low appearances of these transport means.) The models show that:

- The number of regular bicycles at the intersection increases with increasing vehicle traffic volume and the number of pedestrians, when the effect of vehicle traffic is stronger.

- The number of e-bicycles on the roadway increases with the increase of the number of pedestrians and regular bicycles (with a stronger impact of pedestrian traffic); the number of e-bicycles on sidewalks increases with the increase of vehicle traffic and the number of regular bicycles (with a stronger effect of vehicle traffic). The total e-bicycle traffic was affected mainly by the number of regular bicycles, to a lesser extent - by pedestrian traffic, while the impact of vehicle traffic was insignificant.

- For predicting the mobility scooter numbers, a direct effect of pedestrian traffic and an opposite effect of vehicle traffic was ascertained, when the effect of vehicle traffic was stronger.

- For prediction of the total number of ATMs at the intersection, a direct effect of the number of regular bicycles and pedestrians was found, when the impact of bicycle numbers was stronger.

Table 3: Models for predicting ATM numbers in traffic, at urban intersections.

\begin{tabular}{lccccc}
\hline Predicted number of & Intercept & Vehicles $^{\#}$ & Pedestrians $^{\#}$ & Regular bicycles $^{\#}$ & $\mathrm{R}^{2}$ adjusted \\
\hline Regular bicycles & $-6.74^{*}$ & $0.94^{* *}$ & $0.44^{* *}$ & -- & 0.22 \\
E-bicycles, total & -0.76 & 0.32 & $0.17^{*}$ & $0.28^{* * *}$ & 0.41 \\
E-bicycles, on roadway & -0.72 & -- & $0.43^{* *}$ & $0.28^{*}$ & 0.32 \\
E-bicycles, on sidewalks & $-4.16^{*}$ & $0.81^{* *}$ & -- & $0.23^{*}$ & 0.33 \\
Mobility scooters & $3.64^{*}$ & $-0.66^{* * *}$ & $0.31^{* * *}$ & -- & 0.35 \\
ATMs, total & $1.61^{* *}$ & -- & $0.17^{*}$ & $0.33^{* * *}$ & 0.41 \\
\hline
\end{tabular}

${ }^{\#}$ Logarithm of hourly traffic. All models are significant, $p<0.01$. Significant variables: ${ }^{*} p<0.05,{ }^{* *} p<0.01$, ${ }^{* * *} \mathrm{p}<0.001$.

Consistent with the correlation analyses, the models showed that regular bicycles, ebicycles and all ATMs together are in a direct relation with motor vehicles and pedestrians, indicating that ATMs are used for the same destinations in the city as traditional transport means. In contrast, mobility scooters appear at the same sites as pedestrians but their numbers decrease at sites with higher traffic volumes, meaning that 
they tend to avoid heavily-trafficked urban places. In addition, under higher traffic volumes e-bicycles tend to ride more on sidewalks, in spite of the law's prohibition, which may indicate their choice of safer travel conditions at sites with higher safety risks.

\subsection{ATM users' characteristics and behaviours}

Figure 3 shows a summary of the ATM users' characteristics and behaviours while crossing urban intersections that were observed in the study survey. It can be noted that among e-cyclists and e-scooter users, children below 18 presented about a third, young adults aged 19-34 were the majority, 15\% were aged 35-64 and 1\% were older people $(65+)$. The age groups for segway riders were similar, but different for mobility scooter users, where, as expected, the majority were older ages, mostly 65+. Among the ATM users, the majority were males. Similar findings were reported by other studies, from Europe, USA and Australia, where, for example, e-cyclists were typically young men, aged around 30 (except for the Netherlands where the transition to e-bicycles is pertinent to older people).

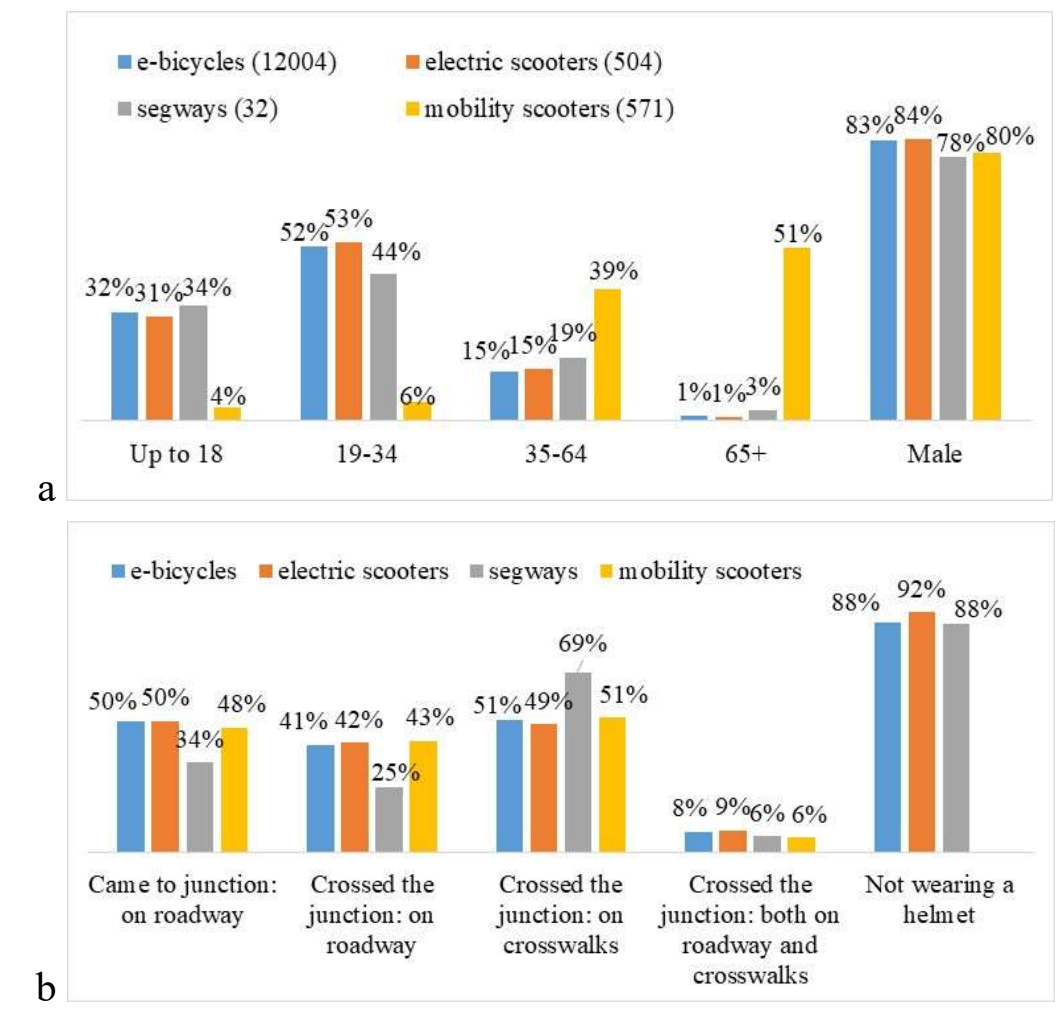

Figure 3: Characteristics (a) and behaviours (b) of ATM users at urban intersections. (No of observations are in parentheses).

About half of the e-bicycles, e-scooters and mobility scooters entered the intersection on the roadway. However, to cross the intersection, most ATM users traveled on sidewalks or combined the roadway and the sidewalks. Among the segway riders, a lower use of the roadway while entering or crossing the intersection was observed. A substantial share of mobility scooters (over 40\%) entered and crossed the intersections on the roadway which must be worrying as this ATM is intended for travel on sidewalks, while their driving on the roadway increases the risk of injury. 
Most of the ATM users rode without helmets. The Israeli law requires helmet wearing for e-cyclists below 18 and for e-scooter riders only, but according to the research literature, non-wearing a helmet is a risk factor for most ATM riders (except for mobility scooters).

\section{Discussion and conclusions}

The use of ATMs, and particularly, e-bicycles, is rising in Israel, in line with the trends reported in other countries. The study findings indicated that the ATM volumes in the cities are not negligible and that most ATM types are used to reach the same travel destinations in the city as traditional transport modes, i.e. motor vehicles, pedestrians and regular bicycles. At sites with higher vehicle and/or pedestrian traffics, more ATM users were observed, thus, strengthening the need to account for the ATM presence both on main traffic routes and on the way to and near pedestrian attractions, in the city. The models developed in the study may assist in the estimation of the expected numbers of ATMs at urban intersections, given the estimates of traditional traffic volumes.

According to Traffic regulations (2016) in Israel, e-bicycles and e-scooters should ride on bicycle paths or on the roadway, mobility scooters and segways - on sidewalks. In practice, a mix of roadway and sidewalks use was observed for various ATM types. Bicycle facilities are not frequent yet in most Israeli towns, hence, e-bicycles and escooters should mostly travel on the roadway, with other motor vehicles. Being on the road, in a mixed traffic, is not perceived by the riders as convenient and safe; as a result, many of them select to ride on sidewalks and cross at pedestrian crosswalks. The study results showed that the higher vehicle volumes, the more ATMs will be on pedestrian facilities. The alternative of using pedestrian facilities may be safer for the riders but creates a danger for pedestrians. Conversely, high shares of mobility scooters and segways were observed on the road, apparently due to the lack of sufficient space for their movement, on the sidewalks. Thus, for better integration of ATMs in city traffic and providing safer travel conditions for all road users, more bicycle facilities and wider sidewalks need to be arranged.

The literature does not suggest separate "strips" for ATMs, in the urban space. To promote a safe use of ATMs in Israeli cities, the main focus should be on a wider application of common bicycle and pedestrian infrastructure, in accordance with the urban streets' design guidelines (e.g. Guidelines, 2009). Better separation between the sidewalks, roadways and bicycle paths, both on street sections and at junctions, will reduce the problem of speed differences and conflicts in the interaction between various road users and will provide less interrupted traffic conditions.

While planning urban facilities, ATM volumes should be accounted for. An explicit consideration of ATM traffic may demand for wider space for sidewalks and bicycle paths, in the street cross-sections, compared to the current practices. In particular, it would be useful to develop typical cross-section solutions for collector urban streets that would consider the ATM needs, along with other road users. With regard to existing streets, among the infrastructure solutions for safer ATM integration in urban space can be suggested: sidewalk extension and adding bicycle paths at the expense of reducing the area dedicated to motor traffic, such as roadway narrowing, reducing the number of vehicle lanes, etc. Moreover, wide implementation of traffic calming measures on local and collector streets will improve safety of all road users.

In parallel, as evident from the study findings, training, enforcement and publicity efforts are needed to improve following the traffic rules by the ATM riders. In particular, 
information campaigns and stricter enforcement are needed regarding the proper use of urban infrastructure by various ATMs. Similarly, the enforcement should be increased to promote helmet wearing by e-cyclists and e-scooter riders, with supporting information programs. Unlike other countries, a third of e-bicycle and e-scooter riders in Israel are youngsters, below 18, who also should be in the focus of the intervention activities of various authorities, through training, education and enforcement.

\section{References}

Blais, D., Rutenberg, U., Suen, L. (2012). "Mobility Scooters for an Ageing Society", $13^{\text {th }}$ International Conference on Mobility and Transport for Elderly and Disabled Persons, New Delhi, India.

Castonguay, S. and Binwa, P. (2006). Pilot Project for Evaluating the Segway HT Motorized Personal Transportation Device in Real Conditions, Centre for Electric Vehicle Experimentation in Quebec (CEVEQ).

Central Bureau of Statistics (CBS) (2015). Road Accidents with Casualties 2014. Part 1: General Summaries, Publication 1611, Jerusalem, Israel.

Cohen, J., Cohen P., West S.G., Aiken L.S. (2013). Applied Multiple Regression/ Correlation Analysis for the Behavioral Sciences, Routledge.

Dozza, M., Werneke, J., Mackenzie, M. (2013). "E-BikeSAFE: A Naturalistic Cycling Study to Understand How Electrical Bicycles Change Cycling Behaviour and Influence Safety", Proceeding of International Cycling Safety Conference 2013, Helmond, The Netherlands.

European Norms EN 15194 (2009). Cycles. Electrically Power Assisted Cycles, EPAC Bicycles.

Fishman, E. and Cherry, C. (2016). "E-bikes in the Mainstream: Reviewing a Decade of Research", Transport Reviews 36 (1), pp. 72-91.

Fyhri, A. and Fearnley, N. (2015). "Effects of E-bikes on Bicycle Use and Mode Share", Transportation Research Part D: Transport and Environment 36, pp. 45-52.

Gertner Institute (2015). "A Position Paper of the National Center for Trauma and Emergency Medicine Research on the Subject of Electric Bicycles and Scooters Injury", Tel Hashomer, Israel.

Gitelman, V., Pesahov, F., Carmel, R., Chen, S. (2017). "Exploring the Characteristics of Potential and Current Users of Mobility Scooters, among Older People in Israel", Transportation Research Part F 46, pp. 373-389.

Griffin, R., Parks, C.T., Rue, L.W. $3^{\text {rd }}$, McGwin, G. (2008). "Comparison of Severe Injuries between Powered and Non-Powered Scooters among Children aged 2 to 12 in the United States", Ambulatory Pediatrics 8 (6), pp. 379-382.

Guidelines (2009). Urban Streets' Design Guidelines, Ministry of Transport and Ministry of Construction and Housing, State of Israel.

Jancey, J., Cooper, L., Howat, P., Meuleners, L., Sleet, D., Baldwin, G. (2013). "Pedestrian and Motorized Mobility Scooter Safety of Older People", Traffic Injury Prevention 14 (6), pp. 647-653.

Johnson, M., Rose, G. (2013). "Electric Bikes-cycling in the New World City: an Investigation of Australian Electric Bicycle Owners and the Decision Making Process for Purchase", Proceedings of Australasian Transport Research Forum 2013, Brisbane, Australia. 
Langford, B.C., Chen, J., Cherry, C.R. (2015). "Risky Riding: Naturalistic Methods Comparing Safety Behavior from Conventional Bicycle Riders and Electric Bike Riders", Accident Analysis and Prevention 82, pp. 220-226.

Lavallee, P. (2004). Pilot Project for Evaluating Motorized Personal Transportation Devices: Segways and Electric Scooters, Centre for Electric Vehicle Experimentation in Quebec (CEVEQ).

MacArthur, J., Dill, J., Person, M. (2014). "E-Bikes in the North America: Results from an Online Survey", Proceedings of the $93^{\text {rd }}$ Annual Meeting of the Transportation Research Board, Washington, DC.

Marcy, N. and Rutherford, G. (2005). Powered Scooter Special Study 7/1/03-6/30/04, Consumer Product Safety Commission, USA.

Miller, S., Kennedy, J., Molino, J., Emo, A., Rousseau, G., Tan, C., Do, A. (2010). Operating Characteristics of the Segway Human Transporter, Publication FHWAHRT-10-025, U.S. Department of Transportation.

Petzoldt, T., Schleinitz, K., Heilmann, S., Gehlert, T. (2017). “Traffic Conflicts and Their Contextual Factors when Riding Conventional vs. Electric Bicycles", Transportation Research Part F 46, pp. 477-490.

Roider, D., Busch, C., Spitaler, R., Hertz, H. (2016). "Segway Related Injuries in Vienna: Report from the Lorenz Bohler Trauma Centre", European Journal Trauma Emergency Surgery 42, pp. 203-205.

Rose, G. (2012). "E-bikes and Urban Transportation: Emerging Issues and Unresolved Questions", Transportation 39, pp. 81-96.

Schepers, J. P., Fishman, E., den Hertog, P., Klein Wolt, K., Schwab, A. L. (2014). "The Safety of Electrically Assisted Bicycles Compared to Classic Bicycles", Accident Analysis and Prevention 73, pp. 174-180.

Thoreau, R. (2015). "The Impact of Mobility Scooters on Their Users. Does Their Usage Help or Hinder? A State of the Art Review", Journal of Transport \& Health 2 (2), pp. 269-275.

Traffic Regulations (2016). Retrieved from https://www.nevo.co.il.law_htm/Law01.

\section{Acknowledgements}

This study was commissioned by the Ministry of Transport and Road Safety in Israel, Chief Scientist unit. 